\title{
El socialismo, la izquierda internacionalista y el naciente comunismo de la Argentina ante la Revolución Rusa de 1917
}

\author{
Hernán Camarero \\ Conicet - UBA \\ hercamarero@gmail.com
}

"La revolución rusa será para nuestros tiempos lo que la revolución francesa para los tiempos modernos". La frase podía leerse el 18 de marzo de 1917 en la tapa del diario La Vanguardia editado por el Partido Socialista (PS) argentino, tres días después del derrocamiento del zar Nicolás II. El acontecimiento era saludado como emblema de la lucha popular por la libertad. Nueve meses después, en cambio, ese mismo órgano de prensa caracterizaba a la Revolución de Octubre como un "golpe de estado" bolchevique que coronaba un desvío del curso natural del movimiento democrático hacia un atajo autoritario. No todos los socialistas opinaban igual. Una fracción izquierdista, cuyos miembros eran expulsados de las filas partidarias y acabaron constituyendo la organización que prefiguró el comunismo local (el Partido Socialista Internacional, PSI), se embanderaba en la causa soviética y glorificaba a los "maximalistas rusos, heroica vanguardia del socialismo internacional".

Este devenir conflictivo de la organización fundada por Juan B. Justo fue una de las expresiones del fenómeno de reconfiguración social, política e ideológica operado en la Argentina bajo el impacto de la Revolución Rusa de 1917, el proceso histórico mundial más significativo del siglo XX. No sólo el movimiento obrero y las izquierdas (incluidos el anarquismo y el sindicalismo) quedaron conmovidos ante los nuevos desafios enunciados desde las insurrectas ciudades de Petrogrado y Moscú. Los eventos revolucionarios de 1917, y los que sucedieron a ellos en los siguientes años, fueron registrados y obligaron a constantes definiciones por parte de las clases dominantes, las derechas y la Iglesia, del nuevo régimen político inaugurado por los gobiernos de la UCR, del periodismo y la opinión pública, de las redes del mundo de la cultura, el arte y las ideas, y de las múltiples colectividades de inmigrantes, entre tantas otras esferas (para un abordaje de las influencias

(Archivos, año VI, ${ }^{\circ} 11$, septiembre de 2017, pp. 13-34) 
de la Revolución Rusa en la Argentina, ver Doeswijk, 2013; Pittaluga, 2015; Camarero, 2017).

El objetivo de este artículo es examinar el impacto producido por la Revolución Rusa dentro de las izquierdas locales: en particular, las caracterizaciones y orientaciones teóricas, políticas y estratégicas adoptadas por el socialismo y el emergente protocomunismo en la coyuntura inicial de aquel proceso histórico. Este análisis brinda elementos para comprender los modos en que estas corrientes entendian el sentido de la revolución y las potencialidades y límites del programa reformista, democrático y revolucionario, así como sus definiciones acerca del sujeto del cambio social y el lugar de las masas en los acontecimientos.

En la década de 1910, sobre todo luego de la Ley Sáenz Peña, el PS quedó definitivamente ordenado bajo un horizonte reformista, cuyas metas eran el perfeccionamiento de las instituciones democráticas, el mejoramiento de las condiciones de vida de las clases subalternas y la modernización del país (sobre el socialismo en el período, ver Walter, 1977; Aricó, 1999; Adelman, 2000; Camarero y Herrera, 2005; Martínez Mazzola, 2015). El PS se integraba al sistema político, apto para la lucha electoral y las lides parlamentarias. Si bien los trabajadores eran mayoria en sus redes de apoyo, el PS no lograba articularse cabalmente en y con el movimiento obrero, al postular una radical separación entre lucha sindical y acción política, y al alejarse de las prácticas de acción directa. Este perfil había sido cuestionado internamente, con algunas escisiones. Durante estos años se incubó una de ellas, con una corriente de izquierda que cuestionó las columnas vertebrales del proyecto reformista. Todo se aceleró en 1917. Los ecos de la Guerra Mundial llegaron a las costas argentinas, mientras de la lejana Petrogrado provenian noticias increíbles. El PS no salió indemne de esta doble conmoción: la guerra y la revolución. De esa crisis emergieron el PSI, primero, y el comunismo, luego (Corbière, 1984; Campione, 2005; Camarero, 2007). Todo ello se produjo bajo el nuevo marco político del país. El presidente Hipólito Yrigoyen inauguraba un régimen político inmediatamente desafiado por un ascenso de las luchas obreras, que no cesaron en su intensidad por lo menos hasta 1921. Este auge de la conflictividad laboral fue acompañado por un proceso de radicalización ideológica y política, en el cual la Revolución Rusa operó como un acicate y un catalizador.

\section{Un nuevo periodo histórico mundial en la agenda del socialismo argentino}

El proceso revolucionario en la tierra de los zares se inició hacia el 8 de marzo y fue ganando intensidad con el transcurrir de esa semana. La primera vez que La Vanguardia refirió a los acontecimientos fue el 16 
de marzo, un día después de la abdicación de Nicolás II y mientras se avanzaba en la formación de un gobierno provisional. ${ }^{1}$ Aquel título en tapa, de dimensiones modestas, con el paso de los meses se convirtió en una sección casi fija, frecuentemente en la segunda página del periódico: "La revolución rusa". Ese día se apeló a una declaración del Labour Party inglés, que aclaraba: "Rodzianko, presidente de la Duma, es el jefe de la revolución estallada, a quien todo el pueblo acompaña". ${ }^{2}$ En verdad, el personaje en cuestión, del partido octubrista, era un politico reaccionario, que ya había sido presidente de la Duma bajo el Imperio. Dos días después el diario ofrecía en su tapa una caracterización integral: "El zarismo ha dejado de existir, iniciándose una nueva era en la historia de Rusia, y acaso en la historia del mundo. Ha caído una dinastía secular, que gobernó siempre autocráticamente, imponiéndose por el crimen y el terror". ${ }^{3}$ Continuaba reivindicando el papel progresivo de las "grandes revoluciones de la historia". Rusia y la Francia de 1789 podian asemejarse. Pero ahora no se trataba de la instauración del dominio de la burguesía, pues era la clase obrera la que se ubicaba al frente:

Nada de extraño sería entonces que la revolución rusa iniciase un nuevo período histórico, el cual habria de caracterizarse por la emancipación social del trabajo. En Rusia podría originarse la revolución socialista, destinada a crear una nueva organización social fundada en los principios de la justicia económica, sin la cual es imposible la existencia real de la libertad individual, ya sea ésta civil o política. (Ibídem)

El PS advertía que en Rusia el proceso seguiría un curso ascendente: "Los obreros no podrian conformarse, en verdad, con la sola conquista del régimen representativo". El artículo concluía: "El socialismo democrático de América ve en la victoria del pueblo ruso el triunfo del proletariado internacional; hace votos por que la revolución renueve la vida de la Rusia libertada de la tiranía zarista a la sombra de la bandera roja, triunfadora en los recientes combates". Pero el PS estaba lejos de una concepción revolucionaria internacionalista, por ejemplo, en relación a la conflagración bélica que sacudía el Viejo Continente: hacía hincapié en que el nuevo gobierno provisional había hecho votos por la continuidad de Rusia en el conflicto y celebraba que hubiera triunfado el partido favorable a la continuación de la guerra. La dirección del PS

1. Nos regimos por las fechas del calendario gregoriano usado en los materiales que trabajamos, las cuales son trece dias posteriores a las fijadas según el calendario juliano empleado en Rusia hasta febrero de 1918.

2. La Vanguardia, 16 de marzo de 1917.

3. La Vanguardia, 18 de marzo de 1917. 
fijó posición pública en torno al tema el 20 de marzo, cuando convocó a una reunión extraordinaria. El Comité Ejecutivo (CE) decidió enviar un telegrama de adhesión a la Duma, invitando al grupo parlamentario a suscribirlo y encargando su redacción al secretario general del partido, Antonio De Tomaso. Dicha misiva, dirigida a Rodzianko, expresaba

su profunda simpatía por el advenimiento de la revolución rusa,
en la cual ve el más grande acontecimiento histórico contem-
poráneo, y al saludar a la Duma, que la ha realizado a nombre
del pueblo y ha proclamado su voluntad de fundar el nuevo
régimen político sobre la base inconmovible de las libertades
públicas para todos y el sufragio universal directo y secreto,
hace votos por que cumpla amplia y valientemente su misión.

El 23 de marzo varios dirigentes del partido hablaron en un acto organizado por el Ateneo Popular. El diputado Antonio Zaccagnini exclamó: "Cuando la noticia de la revolución rusa llegó, hemos temblado, nos hemos quedado perplejos, y nos hemos preguntado si no sería una de esas mentiras que el telégrafo echa a rodar". El senador del Valle Iberlucea (quien venía ejerciendo la dirección de La Vanguardia) también arengaba: “...y ya flamea la bandera roja, esa bandera que une a todos los hombres y a todos los trabajadores, esa bandera prohibida en nuestro país por la ley social. Todo lo cual significa que el socialismo va a vencer primero en Rusia, después en Europa y luego en América". ${ }^{5}$

El PS había cerrado una primera caracterización sobre el carácter democrático-popular del proceso en Rusia. Las referencias a Rodzianko fueron desapareciendo, pero cobraron peso las dirigidas al jefe del primer gobierno, el Príncipe Lvov, y al Ministro de Relaciones Exteriores, Miliukov, ambos del partido kadete. Cuando sobrevino la "crisis de abril" en Rusia, el PS no pudo interpretarla con claridad, sobre todo el carácter de las movilizaciones de obreros y soldados que condujeron a serios enfrentamientos con el gobierno y a la renuncia de Miliukov, tras lo cual se produjo el ingreso de los socialistas moderados a importantes puestos ministeriales. El PS saludó esa incorporación a la administración, procurando no hacer referencia al rechazo de las masas a la guerra. Aunque la convocatoria a elecciones para la asamblea constituyente era incompatible con la movilización de los soldados en el frente, así como la instauración de la jornada laboral de ocho horas lo era con el aseguramiento de la producción industrial para el conflicto bélico, La Vanguardia reivindicaba aquellas causas y a la vez la imperiosa

4. La Vanguardia, 22 de marzo de 1917.

5. La Vanguardia, 25 de marzo de 1917. 
necesidad de que Rusia mantuviera el combate contra Alemania. Las referencias a la revolución siguieron, a partir de la reproducción (con breves comentarios) de los cables telegráficos. ${ }^{6}$ Se siguieron anunciando las siempre buenas novedades sobre la "Rusia democrática", sus promesas de conceder la independencia a Polonia o su decisión de abolir la pena de muerte. ${ }^{7}$

Por el momento, los acontecimientos de Rusia no promovian un eje de diferenciación interno serio en el seno del PS. Ello sí ocurrió a propósito de la posición que el país debía adoptar frente a la Guerra Mundial, correlato de las discusiones que sacudieron a la II Internacional. Lo que se debatió en el PS argentino era si había que promover el fin de los vínculos diplomáticos con el Imperio Alemán o mantener la neutralidad en el conflicto desde una posición "internacionalista". Justo se posicionaba por un "incómodo" neutralismo, mientras abogaba por el librecambio (Poy, 2014). La dirección del partido quedó comprometida con una "defensa de los intereses nacionales", ligados a los de las potencias aliadas (fundamentalmente Inglaterra), con las cuales Argentina aseguraba su exportación de carnes y cereales. El PS mantuvo un delicado equilibrio entre la defensa del comercio exterior y la propaganda del principio de no intervención y la denuncia de la contienda. Este equilibrio se alteró en abril de 1917, con el hundimiento del barco argentino "Monte Protegido", producto de un ataque alemán. Los parlamentarios del partido (el senador Del Valle Iberlucea y los diputados Justo, Bravo, De Tomaso, Repetto, Giménez, Zaccagnini, E. Dickmann, Augusto Bunge y Francisco Cúneo) convocaron al gobierno a adoptar todas las medidas necesarias "para hacer efectivo tan ampliamente como sea posible el comercio argentino en buques de cualquier bandera". ${ }^{8}$

Debió convocarse a un III Congreso Extraordinario para decidir sobre el asunto. En ese tumultuoso encuentro, desarrollado en el Teatro Verdi del barrio de La Boca el 28 y 29 de abril, surgió la izquierda socialista como tendencia pública del socialismo y opuesta a la dirección justista. El partido se dividió: de un lado, la mayoría del CE sostenía la posición de los parlamentarios, contando con el apoyo de Justo; del otro lado, la izquierda "internacionalista", que representaba la minoría en el co-

6. Como con las demás noticias internacionales, el PS informó sobre la Revolución Rusa con materiales de otros órganos de prensa y reproducción de cables telegráficos (de Reuters, Associated Press y otras agencias), fechados en Londres, Nueva York, París, Petrogrado y Moscú, que el diario no corroboraba necesariamente. Existía una decisión respecto a qué se seleccionaba o se hacía hincapié, y en los títulos se detecta una subjetividad; algunos de estos informes eran comentados, trasluciendo cierto sistema de preferencias.

7. La Vanguardia, 1 de abril de 1917.

8. La Vanguardia, 18 de abril de 1917. 
mité (formada por José Fernando Penelón, Juan Ferlini y el concejal metropolitano Agustín Muzzio). Hubo dos proyectos de resolución antagónicos: uno presentado por la mayoría del CE y el otro por la minoría del mismo. La mayoría de la dirección adujo la defensa del comercio exterior como argumento para promover la ruptura con Alemania, aunque otros oradores del sector propiciaron la intervención directa en la Gran Guerra como forma de combatir al peligro mayor, la autocracia germana. Por la minoría, Penelón, Ferlini, Carlos Pascali, Alberto Palcos y Rodolfo Ghioldi reafirmaron que la responsabilidad de las hostilidades era de todas las potencias imperialistas y no del militarismo de uno de los bandos. Justo terció con otro proyecto de resolución, de carácter más conciliador, en el que se afirmaba que el PS no quería una declaración de ruptura de relaciones ni una declaración de guerra, y que no debía tomar ninguna iniciativa parlamentaria sobre el enfrentamiento armado. Penelón defendió la línea de la neutralidad y planteó: "más que un partido de gobierno debemos ser un partido revolucionario" (Corbière, 1984: 35-36). Realizada la elección, de manera impactante fue la izquierda quien obtuvo la victoria, por unos 4.200 votos contra 3.500. En el PS se anidaba el embrión de una fuerte crisis interna, que luego estalló plenamente.

\section{E1 PS frente al Gobierno Provisional, los soviets y el poder dual}

El acto de conmemoración del día internacional de los trabajadores que organizó el PS en Buenos Aires, el 1 de mayo de 1917, le permitió exhibir su posicionamiento en torno a la Revolución Rusa. Varios miles de militantes y trabajadores simpatizantes se agolparon bajo las tribunas levantadas en la avenida Diagonal Sur. La intención era mostrar una imagen de unidad, tras el turbulento congreso culminado dos días antes. La Revolución no aparecía señalada en las pancartas más importantes de los manifestantes, las cuales privilegiaban las demandas pacifistas. Sin embargo, reapareció el motivo ruso. Cobró cuerpo en la arenga de De Tomaso, ${ }^{9}$ para quien lo iniciado en Petrogrado había sido el hecho clave para la "causa del trabajo y de la democracia" en el mundo:

Un régimen político nuevo ha surgido, proclamando la libertad para cientos de millones de hombres, la autonomía política y administrativa para varios pueblos sojuzgados, y afirmando el sufragio universal directo y secreto como la base 
inconmovible de la Rusia nueva. La Internacional contará, de ahora en adelante, con un formidable pilar más.

Recién a partir de mayo La Vanguardia comenzó a registrar el poderío del Soviet, el "Consejo de delegados obreros y soldados". El socialismo no veía a los soviets en contraposición al nuevo poder, sino en una complementación compatible. Celebraba la consolidación del gobierno provisional y que los bandos de la Duma y del Consejo de delegados obreros y soldados ahora se hallasen "bastante menos distanciados". ${ }^{10}$ De la lectura del diario se atisbaba que en Rusia existía una corriente de oposición al curso oficial de la revolución, aunque aún no se alcanzaba a nominarla. El que sí comenzó a ocupar el centro de la atención fue el ministro de Guerra y Marina, Kerenski, un socialista laborista, "garante de la convocatoria de la asamblea constituyente". ${ }^{11}$ Resultaban frecuentes los elogios a otras figuras del menchevismo, como el ministro Tsereteli o el presidente del Soviet de Petrogrado, Chjeidze, y también a los socialrevolucionarios. La línea del PS era la de la unidad de todos los socialistas, de la que luego excluirian a los "maximalistas" de Lenin. Para el PS el proceso ruso debía ordenarse conforme a un horizonte democrático-liberal, republicano y progresista, abierto a las demandas de los trabajadores. Toda idea de doble poder entre el gobierno y el soviet era descartada e invisibilizada. Más aún, se identificaba en aquel primer organismo el reaseguro de la existencia del segundo y el mantenimiento de la guerra contra la autocracia alemana, así como la garantía contra las indebidas tendencias al desborde de la revolución expresados por ciertos grupos. A principios de junio, el diario socialista reproducia una enorme foto de las deliberaciones del Soviet de Petrogrado, y afirmaba: "Al lado del gobierno revolucionario él es, con igual derecho y con no menor fuerza, el parlamento de la revolución, y será, a nuestro juicio, la más fuerte valla contra toda desviación anárquica capaz de poner en peligro a aquella". ${ }^{12}$

Por el momento, la tarea era ganar la guerra contra el Imperio alemán. El diario socialista hacía hincapié en la creencia de que el ejército se estaba reconstituyendo de la mano de Kerenski. Por ello, las "Jornadas de julio" tomaron de sorpresa, una vez más, a La Vanguardia. El partido había pronosticado los progresos de la revolución de la mano del gobierno en colaboración con los soviets para proseguir el conflicto bélico, y en cambio ahora debía dar cuenta del fracaso de la gran ofensiva en el frente, el salto en la descomposición del ejército, las masivas revueltas

10. La Vanguardia, 7 de mayo de 1917.

11. La Vanguardia, 19 de mayo de 1917.

12. La Vanguardia, 6 de junio de 1917. 
que presionaban al Soviet a tomar el poder, la renuncia de Lvov y la asunción de Kerenski como nuevo primer ministro. Para el PS, la clave era asegurar la "suprema autoridad del gobierno provisional".

¿A partir de qué momento el PS advirtió la existencia del bolchevismo como corriente autónoma y revolucionaria del socialismo ruso? Fue desde junio, cuando esa corriente fue ganando la mayoria de delegados en el Soviet de Petrogrado. La Vanguardia empezó a identificarla con las posiciones más radicales, junto a las de los anarquistas. Huido a Finlandia, Lenin fue haciéndose fantasmal en el diario, quien pareció dar crédito a la acusación de que estaba al servicio de la potencia extranjera rival: "El consejo de obreros y soldados ha resuelto que los maximalistas acusados de incitar a la rebelión o de haber recibido dinero alemán sean juzgados públicamente. Se declaró inadmisible que el extremista Lenine [sic] y sus colegas escapen a la acción de la justicia". ${ }^{13}$ En septiembre destacaba la caracterización del ex activista revolucionario Vladimir Burtsev acerca del bolchevismo como sirviente de Berlin: "el partido maximalista es un instrumento de Alemania, de la cual recibe dinero. Sus jefes $[\ldots]$ son los principales culpables de la descomposición de Rusia y de la debacle del ejército ruso". ${ }^{14}$ Se multiplicaron las noticias desopilantes, las mismas que podian hallarse en el resto de la prensa mundial. Por ejemplo, la que señalaba que, en una reunión privada de la Duma, Vladimir Purishkévich (un referente de la tendencia nacionalista y antisemita) había declarado: "Lenine falleció en Zurich en el año 1916 y que el seudo Lenine es el señor Zaderblum, ex amigo de Lenine". ${ }^{15} \mathrm{Se}$ trataba de un dislate: se lo confundia con Mártov (apodo del judio Yuli Zederbaum), gran amigo de Lenin pero que luego pasó a rivalizar con él, convirtiéndose en uno de los líderes del menchevismo. La Vanguardia transcribió ese tipo de cables en esos meses. La primera vez que hizo conocer el nombre de los "bolshevikistas" (colocado así, entre comillas, dando cuenta del exotismo del término) fue a comienzos de septiembre. Se los identificaba como la "extrema izquierda" y como "partidarios del programa máximo". Al grupo nucleado en torno al periódico Pravda, que dirigia Lenin y Grigori Zinóviev, se lo caracterizaba como inspirado en planteos anarquistas: "Es de tendencias extremadamente violentas. Al volver a Rusia, Lenine ha pronunciado un discurso sensacional, para afirmar la superioridad de las teorias de Bakounine sobre las de Marx". ${ }^{16}$

Ya en el período previo al desenlace de la Revolución bolchevique, La Vanguardia informó del levantamiento de Kornílov, hacia fines de

13. La Vanguardia, 30 de julio de 1917.

14. La Vanguardia, 5 de septiembre de 1917.

15. La Vanguardia, 6 de septiembre de 1917.

16. La Vanguardia, 9 de septiembre de 1917. 
agosto o principios de septiembre, de manera condenatoria. Antes le había dispensado cierta aprobación, sobre todo a sus proclamas en favor del reordenamiento militar para alcanzar la victoria en la guerra con Alemania. Ahora se reprobaba la insubordinación del "generalísimo", sus intentos por asumir todos los poderes civiles y militares del país y su proyecto de conformar un nuevo gobierno dictatorial. El diario fijó posición en defensa de la administración de Kerenski, editorializando con una teoria de las dos acechanzas: la del bolchevismo, de un lado; la de los contrarrevolucionarios, del otro. ${ }^{17}$

A comienzos de octubre, una larga nota de tapa, perteneciente al dirigente partidario y periodista Ricardo Sáenz Hayes, cubria de elogios la figura de Kerenski, definido como "el más bello símbolo del héroe civil", "suave con los humildes y aterciopelado con las damas", "el honor de su patria, el salvador de sus pueblos, el orgullo de los hombres libres y bien nacidos", al que contraponía con el "agitador Lenine", quien ya desde Suiza conformaba "un grupo minúsculo" que "realizaba laboriosas propagandas para que la clase trabajadora se declarara adversa a la guerra". ${ }^{18}$ La dirección mayoritaria del PS se colocaba en el campo del ministro. Pero el ala izquierda ya tomaba distancia también de esa posición y comenzaba a pronunciarse a favor de Lenin.

Habia ocurrido algo importante: la corriente de izquierda socialista se corporizaba cada vez más como línea opositora interna. Desde comienzos de agosto había lanzado un órgano de prensa propio, bajo la dirección de Penelón, La Internacional, el que acabó siendo, durante las siguientes casi dos décadas, el periódico oficial del PSI y el comunismo local. El grupo también comenzó a editar la Revista Socialista. La crítica a las concepciones reformistas del PS se había profundizado. Se volvía a centrar el ataque en una influencia que se entendía como clave, la del alemán Bernstein, "un retrógrado que labora contra el socialismo", al apostar "todo al movimiento y nada al fin último" de éste, como sostenía Penelón en la editorial del primer número de La Internacional. ${ }^{19}$ También cuestionaba la posición partidaria en relación a la Revolución Rusa, sobre todo el apoyo al gobierno provisional, mientras observaba con creciente simpatía la posición de los bolcheviques: "estamos con Lenin y no con Kerenski". ${ }^{20}$

17. La Vanguardia, 12 de septiembre de 1917.

18. La Vanguardia, 5 de octubre de 1917.

19. La Internacional, 5 de agosto de 1917. Las criticas al bernstenianismo en el PS ya se habian manifestado en Palabra Socialista, el periódico impulsado por el ala izquierda entre 1912-1914 (Diaz, 2015).

20. La Internacional, septiembre de 1917. 


\section{Desenlaces y crisis en torno a la guerra y la revolución}

El PS no sólo tenía el desafío de interpretar y posicionarse ante la Revolución Rusa. El otro gran fenómeno de la arena internacional, la guerra, continuaba conmoviendo al país y al propio partido. Tras el ataque alemán al velero argentino "Toro" y el incidente con el conde Luxburg, que llevaron al conservador Joaquín V. González a solicitar al gobierno de Yrigoyen la suspensión de relaciones diplomáticas con Alemania, volvió a estallar el conflicto dentro del PS. Sus legisladores apoyaron esa propuesta, esgrimiendo sus posiciones aliadófilas y contraviniendo las disposiciones del III Congreso Extraordinario. Lo hicieron los diputados y el único senador de que disponía el partido, Del Valle Iberlucea. ${ }^{21}$ Quedó en debate el desempeño del senador y los diputados socialistas, y el control que debía ejercerse sobre los mismos, pues con aquel voto, argumentaba la izquierda, los parlamentarios, avalados por la mayoría del $\mathrm{CE}$, violaban la democracia al desconocer el mandato que habian recibido de un congreso soberano. La discusión se expresó en La Vanguardia de septiembre a diciembre de 1917, participando las grandes figuras de ambas fracciones contendientes y también cientos de militantes de base del partido que a veces matizaron las posiciones de los bandos en pugna (Campione, 2005: 25-51).

Pero, además, ya la tendencia de izquierda podía expresarse desde $L a$ Internacional, que se lanzaba a una impugnación global a la dirección del PS. Frente a las declaraciones de ésta, a propósito de la posición ante el pedido de suspensión de relaciones diplomáticas con Alemania, cuando afirmó que no se quería ser sólo un partido de oposición sino también de gobierno, la izquierda señaló el peligro de desviar al movimiento socialista "hacia la negación de su política de clase, de su misión histórica que consiste en orientar la clase trabajadora hacia su emancipación integral y no en procurar su tutela solidarizándola con

21. La trayectoria de Del Valle Iberlucea presentó fuertes virajes. Sus posiciones en la cuestión bélica estaban a la derecha en el partido: quedaron expuestas en sus obras La guerra europea y la politica internacional, de 1914, y La cuestión internacional y el Partido Socialista, de 1917. Pero anteriormente, este profesor de derecho internacional en la Universidad Nacional de La Plata y militante del partido desde comienzos del siglo, levantaba posiciones a la izquierda del justismo. Se advierte en las publicaciones por él fundadas, Revista Socialista Internacional y Humanidad Nueva, atentas a cuestiones de filosofia y derecho, con críticas a las posturas bernstenianas en el socialismo. Había mirado con simpatías la dinámica de los jóvenes de la izquierda socialista. Y tiempo después brindó su apoyo a la Revolución Rusa, y por ello fue desaforado del Senado en 1921.Ver Del Valle Iberlucea, 1934; Marianetti, 1971; Corbière, 1987; Becerra, 2009. 
la clase capitalista, haciéndola copartícipe de un gobierno burgués". ${ }^{22}$ Repudiaba el camino del acceso al poder por la vía electoral: "El único sentido posible de las palabras de Marx al referirse a la conquista del poder, es la conquista revolucionaria para establecer la dictadura proletaria a fin de realizar la transformación histórica que el socialismo persigue". Advertía acerca de la pérdida del carácter obrero y revolucionario del PS, devenido en un partido al estilo radical europeo, ajeno a la lucha de clases e identificado con la defensa del Estado nacional desde un chauvinismo que negaba el carácter interimperialista de la guerra. Finalmente, denunciaba la falta de democracia interna y el fenómeno de oligarquización, que dejó los resortes de la vida partidaria en manos de un puñado de "doctores", los cuales dominaban el CE y monopolizaban la representación parlamentaria y La Vanguardia.

Con el objetivo de tensar aún más la confrontación interna, la corriente internacionalista reclamó un nuevo congreso extraordinario que tomara medidas contra los parlamentarios. Pero los legisladores socialistas, procurando evitar aquella convocatoria, a principios de octubre realizaron un giro de la discusión: presentaron como opción la renuncia a sus bancas y pidieron al $\mathrm{CE}$ que el voto general de los afiliados juzgara su actitud. El carácter mismo de la consulta incrementaba las posibilidades para un triunfo de los parlamentarios, pues de ganar la moción contraria, el PS habría perdido sus bancas, dejando amenazada su principal base de sustentación política. El concejal Antonio Mantecón cuestionó el chantaje: “¿Por qué el Comité Ejecutivo en vez de llamar a un voto general no llamó a un congreso extraordinario?”. ${ }^{23}$ De manera obvia, el resultado fue favorable al grupo parlamentario (5.345 votos contra 909, y 72 abstenciones y más de 2.000 ausentes). Los internacionalistas no supieron calibrar la capacidad de reacción y maniobra de la vieja conducción justista, que otra vez sobrevivió a un desafio interno, preparándose para ajustar cuentas con la tendencia de izquierda a la que acababa de propinarle un certero golpe. Debió hacerlo en medio del nuevo torbellino en el que cayó Rusia.

El PS argentino quedó completamente sorprendido por la insurrección de octubre. Las primeras informaciones en su prensa aparecieron en la edición del 8 de noviembre, con un desordenado conjunto de cables fechados el día anterior, con los acontecimientos aún en desarrollo. El diario señalaba que "un destacamento naval armado, bajo las órdenes del comité revolucionario maximalista, ocupó la oficina de la agencia

22. La Internacional, 27 de octubre de 1917.

23. A. Mantecón, El Partido Socialista y la cuestión internacional, Buenos Aires, Imprenta Sarandi 374, 1917, p. 14. 
telegráfica oficial de Petrograd". ${ }^{24}$ Desde el inicio la insurrección fue caracterizada como una asonada armada de unos pocos miles, bajo responsabilidad del bolchevismo. Los datos eran contradictorios, mostrando una situación abierta. Al día siguiente, La Vanguardia confirmaba la sucesión de eventos: el derrocamiento de la administración de Kerenski, el ataque al Palacio de Invierno por parte de "las tropas del Soviet", la realización del "congreso general de los obreros y soldados" (aludía al II Congreso Panruso de los Soviets), el arresto de los ministros y el control de Petrogrado en manos de los maximalistas, quienes habian iniciado las tratativas para una "paz inmediata", la resolución del problema campesino y la convocatoria a la asamblea constituyente. Transcribía una proclama: "Depusimos al gobierno, quien se irguió contra la revolución. La única autoridad es, actualmente, el comité revolucionario". ${ }^{25}$ Ya desde ese momento se definía a los hechos como un "golpe de Estado sin verter sangre".

El PS debía lidiar con un panorama confuso, en base a noticias en su mayoría falsas o distorsionadas. Durante varios días señaló en su diario que las noticias eran "satisfactorias" y hacian esperar que "el efimero reinado de los maximalistas toca a su fin". El nivel de distorsión de la realidad se acentuaba, afirmándose que las fuerzas de Kerenski ya estaban en Petrogrado y eran "virtualmente dueñas de toda la ciudad", para culminar: "Se prevé el fin próximo del movimiento maximalista". ${ }^{26}$ Varias de las noticias transcriptas en La Vanguardia eran equivocadas: Kerenski nunca pudo tener el control de Petrogrado ya que jamás llegó a reingresar a la ciudad pues sus tropas alcanzaron a combatir en Tsárskoye Seló (la Villa de los Zares), a 24 kilómetros de la urbe, donde no fueron victoriosas, sino derrotadas por la Guardia Roja. Con el paso de los días el diario seguía insistiendo: "La población parece retirar su confianza a Lenine y a Trotsky", "la demostración de autoridad de los "bolsheviki" disminuyó en forma considerable", mientras se informaba en forma fantasiosa sobre un total control de Moscú por parte de las tropas de Kerenski y la inminente formación de un nuevo gobierno de coalición sin la presencia de los seguidores de los "agitadores Lenin y Trotsky" ${ }^{27}$ Recién diez días después, desde el 19 de noviembre, se aceptaba que los bolcheviques eran "dueños de la situación" y controlaban las dos grandes ciudades del país..$^{28}$ Desde ese entonces La Vanguardia se dispuso a establecer una opinión de fondo sobre los hechos. Lo hizo

24. La Vanguardia, 8 de noviembre de 1917.

25. La Vanguardia, 9 de noviembre de 1917.

26. La Vanguardia, 15 de noviembre de 1917.

27. La Vanguardia, 17 de noviembre de 1917.

28. La Vanguardia, 19 de noviembre de 1917. 
a través de la pluma de Arturo Havaux, integrante del equipo de redactores del diario:

Las noticias de Rusia, contradictorias durante los primeros dias del golpe de estado de los maximalistas, son ahora bastante claras desde las distintas fuentes de que proceden. Kerensky derrotado y desaparecido, sin que se conozca su paradero; los maximalistas en el poder, dueños de Petrograd y de Moscú, a pesar del descontento que sus procedimientos provocan; la anarquía en Finlandia; el ejército, disuelto o desorganizado; la lucha de los partidos con la perspectiva de la inevitable guerra civil y el espectro del hambre que amenaza, constituyen el espectáculo que ofrece hoy la nación moscovita. ${ }^{29}$

Si la incapacidad politica había conducido al fracaso al gobierno de los Lvov y los kadetes, con la llegada de Kerenski y los socialistas moderados se había inaugurado la etapa de los "estadistas prácticos", quienes habían hecho todo lo posible para encauzar el proceso. Con la derrota del levantamiento de Kornílov parecía que se consolidaba el camino de la república y las reformas. Sin embargo, había fracasado. ¿Por qué?:

la agitación ultrarrevolucionaria contagió los espíritus de los descontentos de nacimiento contra todo lo establecido y normal, y logró hacer desviar la revolución de la pauta lógica y sensata que, a mi parecer, le estaba dando el gobierno provisional derrotado. Vemos el resultado de ello: Rusia sin gobierno reconocido por las demás potencias, ni por el mismo pueblo ruso; el desquicio más completo en la administración del país.

Según el periodista del PS, Rusia no podía saltar etapas intermedias, y se preguntaba: “¿Cómo iríamos a creer los que eso sabemos que el pueblo ruso, que hasta ayer vivió bajo la amenaza del knout, y cuya ignorancia es supina, puede dar un salto que lo coloque en un plano superior de vida democrática al de Inglaterra y Francia?”. La conclusión era elocuente: "Pueden Lenine y Trotsky concebir ese salto: el pueblo ruso no puede darlo". El cierre de la reflexión daba cuenta de lo que más desvelaba al PS, es decir, la impugnación a la decisión del flamante gobierno soviético de retirarse de la guerra. 


\section{Surgimiento de un partido socialista de izquierda adherente a la Revolución de Octubre}

Mientras ocurría el triunfo de la insurrección impulsada por el bolchevismo, el PS debía administrar la ruptura de su corriente de izquierda. En la consulta interna el oficialismo había logrado una victoria para la posición de sus parlamentarios, pero los disidentes movieron sus piezas. En octubre constituyeron un Comité pro defensa de la resolución del III Congreso Extraordinario. Pero, aprovechando el respaldo obtenido en aquella votación, la dirección mayoritaria lo disolvió por "ilegal, disolvente y anarquizante". Penelón y Ferlini renunciaron al CE, el cual procedió en noviembre y diciembre a efectivizar la separación de los opositores. Se conformó un Comité de Relaciones de los Centros Socialistas Disueltos y Minorias Expulsadas, que convocó a un Congreso de Expulsados del PS, el cual acabó sesionando el 5 y 6 de enero de 1918 en el salón porteño "XX de Septiembre". ${ }^{30}$ La mayoría de los asistentes provenían de la Capital Federal, de la Agrupación Gráfica y algunos pocos de las provincias de Buenos Aires, Santa Fe y Córdoba. Los delegados representaban a unos 750 militantes, pertenecientes a veintidós centros. Es decir, sólo un pequeño sector de quienes habian respaldado a la izquierda en el debate sobre la guerra acompañó a los internacionalistas: nueve meses antes, en el congreso del teatro Verdi, dicha corriente había obtenido cuatro mil votos a su favor. En el nuevo partido predominaba la impronta juvenil. Uno de los pocos diarios nacionales que cubrió el evento, informó: "llama la atención en este congreso el hecho de que predomina casi en absoluto el elemento joven". ${ }^{31}$ Muchos venian de una inserción reciente en el PS y carecian de la trascendencia pública del oficialismo. La excepción era la presencia del grupo de veteranos cuadros obreros alemanes: Augusto Kühn, Guillermo Schulze, Gotoldo Hummel y los hermanos Germán y Enrique Müller.

La nueva organización fue denominada Partido Socialista Internacional (PSI), después de un debate entre otras opciones (por ejemplo, nominarlo Partido Socialista Revolucionario). Entre sus integrantes habia una mayoritaria presencia de obreros, empleados, docentes y estudiantes, junto a algunos pocos profesionales y otros afiliados provenientes de la clase media. De conjunto, el perfil social del colectivo era de un carácter más plebeyo que el de la fuerza liderada por Justo. El PSI inicialmente intentó disputar de lleno la legitimidad histórica al PS, sobre todo su nombre y la enunciación de la causa socialista. En aquel congreso de enero de 1918 se aprobaron la declaración de principios

30. La convocatoria apareció en La Internacional, 6 de diciembre de 1917.

31. La Razón, 5 de enero de 1918. 
(que retomaba la adoptada en 1896), el programa mínimo y el estatuto del partido. Se estableció la obligatoriedad para todos sus afiliados de activar en sus sindicatos. Y se lanzó un manifiesto de constitución de la nueva fuerza, donde se sostenía: "El Partido Socialista ha expulsado de su seno, deliberada y conscientemente, al socialismo. No pertenecemos más al Partido Socialista. Pero el Partido Socialista no pertenece más al socialismo". ${ }^{32}$ La Vanguardia, respondió con desdén al grupo escindido: "Nadie como nosotros sabe que no basta decirse socialista, ni parecerlo, para serlo en realidad. ¿No estamos asistiendo aquí a la triste farsa de un puñado de individuos que pretenden hacer maximalismo difamando al Partido Socialista y tratando de restarle fuerzas, para mayor gloria y provecho de la reacción burguesa, clerical y militarista que representa la facción titulada radical?". ${ }^{33}$

En el manifiesto fundacional, el PSI colocaba la cuestión del posicionamiento ante el conflicto bélico como asunto decisivo para explicar la ruptura, y hacía explícita su adhesión a la tendencia internacionalista impulsada desde 1915-1916 por Lenin, Trotsky y Rosa Luxemburgo:

El Partido Socialista, al aprobar la guerra capitalista, rompe por completo su solidaridad con los socialistas que, en medio de los horrores de la conflagración, trabajan infatigablemente en toda Europa y Estados Unidos por la instauración de la paz y del socialismo, conforme a las resoluciones de los congresos socialistas de Stuttgart, Copenhague y Basilea, confirmadas por los recientes congresos de Zimmerwald y Kienthal. ${ }^{34}$

¿Qué lugar ocupó la Revolución Rusa en el proceso de constitución del PSI? Es evidente que el largo ciclo de desarrollo de la corriente de izquierda que acabó formando el PSI preexistió a la toma del Palacio de Invierno, y comenzó a estructurarse como espacio alternativo global con la aparición de La Internacional, apenas tres meses antes de dicho evento. Pero en el proceso de diferenciación total entre el oficialismo y la disidencia, las formas de abordar el proceso ruso ya eran distintas desde antes: no hubo un extenso periodo de transición para clarificar esta desigual postura. Por ello, en su manifiesto constitutivo de enero de 1918, el PSI consideraba la posición del PS frente a los hechos de Petrogrado el ingrediente decisivo para la erección de una valla entre ambos partidos: "para hacer más patente esa absoluta desvinculación

32. PSI, Historia del socialismo marxista en la República Argentina. Origen del Partido Socialista Internacional, Buenos Aires, 1919, p. 56.

33. La Vanguardia, 14 de febrero de 1918.

34. Historia del socialismo marxista..., ob. cit., p. 57. 
del Partido Socialista con el socialismo, el órgano oficial del partido, en un comentario sobre los maximalistas, llamó a éstos "los peores enemigos de la Revolución Rusa", como si el advenimiento al poder del primer gobierno genuinamente socialista que registra la historia fuera una gran desgracia". La disonancia de los planteos eran claros, pues, mientras el PS aludía a un desafortunado golpe de Estado, el PSI retrataba la faena de "un pueblo que se propone firmemente concertar la paz mundial, derrocar a la burguesía e implantar el tan anhelado reino del proletariado socialista...”. En fin, cuando el PSI buscó concluir su manifiesto y completar su identidad pública, eligió la Revolución Rusa como su desiderátum:

Un ardiente e impetuoso soplo revolucionario parece cruzar triunfante por el planeta. Ha comenzado en Rusia y se extiende hacia todos los rincones del mundo. Su móvil: la instauración del socialismo. Con la mirada elevada en tal alto ideal queremos ser en esta sección de América, los agentes eficientes, activos, de esta hondísima transformación revolucionaria. ${ }^{35}$

Estas formulaciones ocurrian cuando el régimen soviético estaba apenas en ciernes. En la progresiva construcción del perfil del PSI la adhesión a la Revolución Rusa fue alcanzando una notable preeminencia. El partido ganó el espacio público con las acciones de solidaridad con el proceso soviético. El 7 de noviembre de 1918, junto a otras organizaciones obreras y de izquierda, el PSI impulsó en Buenos Aires una marcha en conmemoración de la insurrección de octubre, en la que participaron unas diez mil personas, y que luego se convirtió en una suerte de efemérides anual impostergable. Todo el análisis que el partido hacía de la situación internacional fue tamizado por la dinámica del movimiento iniciado por los bolcheviques. Con la firma del armisticio que puso fin a la Guerra Mundial, pocos dias después, el CE del PSI expresó: "Ratificar su solidaridad con el gobierno de los "soviets" de Rusia y congratularse por el movimiento maximalista que en Bulgaria, Austria-Hungría y Alemania se propone establecer un estado de cosas idéntico al de la nueva Rusia, augurando se extienda por todo el universo". ${ }^{36}$ En el posterior manifiesto que celebraba la culminación de la conflagración bélica, saludaba: "¡Gloria a los maximalistas rusos! Gracias a su acción la horrenda carniceria mundial se ha acortado en algunos años, ahorrando a la humanidad varios millones de muertos", aludiendo al hecho de que la Revolución de Octubre había diseminado

35. Historia del socialismo marxista..., ob. cit., p. 58.

36. Historia del socialismo marxista..., ob. cit., p. 64. 
"las semillas de la revolución social" y provocado el derrumbe de los imperios centrales. Y culminaba su proclama:

Los maximalistas rusos, heroica vanguardia del socialismo internacional, han echado los cimientos de una Humanidad nueva, la Humanidad redimida del porvenir, sin castas ni privilegios sociales, sin guerras y sin déspotas. Firmes en nuestros principios pacifistas e internacionalistas, trabajemos en nuestro medio por el advenimiento de hora tan venturosa. [...] y preparemos la transformación revolucionaria de la sociedad americana. $^{37}$

A fines de 1918 el PSI publicó la constitución de la República Socialista Federativa Soviética de Rusia. ${ }^{38}$ Y comenzó a realizar campañas por su reconocimiento por parte de la Argentina, agitando esa consigna en el periódico y en sus proclamas electorales: Ferlini, quien había sido electo como el primer concejal del partido, en julio de 1920 pidió pronunciamiento en ese sentido al Concejo Deliberante de la Capital Federal para que lo solicitase al Congreso Nacional. En el campo de la propaganda, la labor fue muy vasta. En 1919 se publicaron escritos de Lenin y Zinoviev sobre el socialismo, la guerra y la revolución: De la Revolución Rusa. ${ }^{39}$ El PSI también consideró auspiciosa la edición en Buenos Aires de Documentos del Progreso, revista que cubría la realidad del régimen soviético, y reproducía escritos de sus autoridades. Bajo la dirección de Simón Scheimberg y Aldo Pechini, se publicaron 45 números entre agosto de 1919 y junio de 1921. Desde esa publicación salieron varios folletos y libros de Lenin, Trotsky, Zinóviev y Radek.

\section{La Revolución Rusa como rechazo y como principio identitario en la izquierda: del socialismo al comunismo}

Recapitulemos y profundicemos la reflexión sobre algunos de los ejes tratados. Tras la caída del zarismo, el PS argentino apeló a una comprensión de los acontecimientos bajo un diagnóstico general: se estaba ante los inicios de una "revolución socialista" (una era de transformación a favor de los trabajadores) a escala mundial. ¿Cuál era la concepción del partido acerca del carácter de la revolución, tanto en Rusia como en Argentina? En tanto se derrocase un régimen despótico, su legitimidad

37. Historia del socialismo marxista..., ob. cit., pp. 65-66.

38. Constitución de la República Rusa Socialista Federal de los Soviets, Buenos Aires, Ed. Marxista, 1918.

39. G. Zinoviev y N. Lenine, De la Revolución Rusa, Buenos Aires, PSI, 1919. 
histórica estaba presente. Por ello se aludía a una revolución democrática, que abría curso a la conquista de las libertades individuales, civiles y políticas. Pero a la vez implicaba la lucha por la justicia social y las reformas a favor de los trabajadores, y era alli donde asumía un sentido vagamente socialista, pero de orientación indeterminada, sin temporalidad, tareas, sujetos o procesos claramente establecidos. Esa revolución no estaba limitada a un tiempo corto y rupturista, era identificada como un proceso largo, de gradual expansión de los valores y los logros materiales de la libertad y la igualdad, conquistados en un camino de reformas. Entendido de este modo, reforma y revolución quedaban concatenadas, no excluyentes.

El partido de Justo reconocía la participación de las masas en el proceso de la Revolución Rusa (si bien alertando sobre los caóticos "desbordes"), pero dirigía su mirada preponderantemente en las representaciones políticas, sin calibrar cabalmente el peso del protagonismo popular. Era expresión de la orientación institucionalista del PS, que tendía a no encontrar carácter positivo en las formas de acción directa y violenta de las masas. Aunque entendia al sujeto social participante como clase trabajadora en lucha por sus derechos, antes que como una suerte de pueblo cívico activo. Sólo ocasionalmente diluía a la clase obrera en un sujeto más indeterminado, al sumarle los campesinos y otros sectores oprimidos. Es decir, se trataba de una explicación reformista e institucionalista, pero en términos de clase.

En el balance del PS lo acaecido en octubre era un golpe de Estado, protagonizado por agitadores sin respaldo popular, que habian extraviado el curso sensato de la construcción de una república abierta a las reformas democráticas y atenta a sus responsabilidades en la guerra, para reconducirlo a la aventura de un gobierno extremista, que dejaría como consecuencia el marasmo del hambre, el desquicio en la administración, la guerra civil y un armisticio indigno con la autocracia alemana. En esta visión, la saga abierta en Petrogrado se había desnaturalizado y había perdido su destino histórico, descarriándose hacia la confrontación social y la política violenta. Reconocían una suerte de periodo ascendente hasta el levantamiento de Kornílov: hasta ese periodo todas las informaciones sobre el tema en La Vanguardia estuvieron bajo el título "La revolución rusa". Luego de ello, quedaron bajo el rótulo "La situación en Rusia". La revolución verdadera era la de febrero y su estela, mientras que lo siguiente era la anarquía, la inconcebible lucha por el poder entre soviets, gobierno y partidos, y finalmente el golpe de Estado. Detrás de esta idea de desvío, ¿no queda exhibida la ausencia de una genuina teoría de la revolución en el socialismo argentino y, en cierto sentido, algunos de los límites de su instrumental teórico y programático? El partido no alcanzó a definir plenamente la dinámica del 
proceso revolucionario, las estrategias puestas en juego, las fases, las fuerzas motrices, los aliados y adversarios de cada orientación. Como ocurrió con la mayor parte de la II Internacional, al socialismo local se le dificultó la comprensión de las contradicciones y dilemas que esmerilaron al gobierno provisional, fortalecieron la autonomia de los soviets y encumbraron a los bolcheviques. Era sintomática la acusación hacia estos últimos como bakuninistas, fuera de la tradición socialista. Para el PS no podía existir un socialismo revolucionario: lo consideraba una contradicción de términos. Y por eso el proceso de expulsión-escisión del ala de izquierda internacionalista aparece como inevitable.

Poco después, más definido el curso del proceso soviético, el PS profundizó una impugnación global a la revolución impulsada por los bolcheviques, oponiendo la dictadura del proletariado a un verdadero camino socialista democrático. En 1919 De Tomaso asistió al Congreso de Berna de la Internacional Socialista, teniendo la oportunidad de entrevistarse con Pável Axelrod, Eduard Bernstein y Alexander Kerenski. Su periplo europeo fue reconstruido con las crónicas publicadas en $L a$ Vanguardia y finalmente editadas en el libro La Internacional y la revolución. "La práctica de la democracia, en el orden político y en el orden económico, no se improvisa, y a ella no puede sustituirse la dictadura de ninguna minoría por más iluminada que se considere", sostenía De Tomaso. ${ }^{40}$ También resultaba clave el método: "La violencia de arriba no puede reemplazar la conciencia de las masas. Y su culto durante las revoluciones rusa y alemana por una parte de los revolucionarios, que han sustituido o quieren sustituir las bayonetas, las ametralladoras y los automóviles blindados a las asambleas constituyentes, es otra de las consecuencias de la guerra". Para el dirigente del PS la "llamada dictadura del proletariado" era una experiencia fallida, que "de simple pasaje perdido en el libro de un teórico del socialismo, de postulado más o menos vago", se había convertido en la excusa para el golpe de Estado y la sustitución de la democracia y la voluntad de la mayoría.

Por otra parte, al PSI, aún en su consustanciación con la emergente dictadura del proletariado en Rusia, le costó definir una identidad política homogénea. Se halló en tensión y reformulación interna durante sus tres años de existencia. Inicialmente, pretendió disputar su razón de ser al propio PS, presentándose como el genuino representante de un proyecto socialista que aquella organización habria mancillado. Pero ese partido de rasgos revolucionarios, hostil al parlamentarismo y orientado hacia la lucha de clases que se pretendía conformar no era fácil de plasmarlo en los marcos tradicionales heredados de la Segunda Internacional.

40. Antonio De Tomaso, La Internacional y la revolución, Buenos Aires, La Vanguardia, 1919, p. 122. Agradezco a D. Ceruso el acceso a esta fuente. 
Finalmente, se conocieron las resoluciones del II Congreso de la Internacional Comunista (IC), concluido el 7 de agosto de 1920 en la capital soviética. Entre ellas, estaban las 21 condiciones de la "Circular Zinóviev", estipulando los requisitos que las organizaciones miembros debían cumplimentar, incluso, adaptar su propia denominación. Por esta razón el PSI convocó a su I Congreso Extraordinario, celebrado el 25 y 26 de diciembre en el salón del Circolo Mandolinístico de Buenos Aires, con un escenario adornado por dos inmensas banderas rojas y un escudo de la Rusia soviética. Se presentó el proyecto que proponía acatar la citada Circular. Ello implicaba un estatuto que suponía una transformación definitiva de la fuerza, intentando convertirla en una organización disciplinada, orientada a la conspiración revolucionaria y la acción clandestina, un proceso que experimentó fuertes desventuras, como se observó en los siguientes años. ${ }^{41}$ Desde ese momento pasó a llamarse Partido Comunista, Sección Argentina de la Internacional Comunista. En su manifiesto la referencia a 1917 fue inevitable: "La Revolución Rusa es nuestra antorcha. Ella encierra un caudal inmenso de experiencias revolucionarias. La Revolución Rusa tiene un valor universal. Sus principios son los únicos que pueden servir de base a las próximas revoluciones proletarias en todos los países". ${ }^{42}$ La constitución del PC y la adhesión a las pautas políticas, programáticas y organizativas provenientes de la IC supuso un salto en su homogeneización, que exige un análisis detenido. El modelo de Octubre fue el hilo rojo que terminó galvanizando a la nueva corriente, dotándola de un principio de identidad y diferenciándola del resto de las culturas políticas de izquierda.

\section{Bibliografia}

Adelman, Jeremy (2000), “El Partido Socialista Argentino”, en Mirta Z. Lobato (dir.), El progreso, la modernización y sus limites (1880-1916), en Nueva Historia Argentina, t. V, Buenos Aires: Sudamericana.

Aricó, José (1999), La hipótesis de Justo. Escritos sobre el socialismo en América Latina, Buenos Aires: Sudamericana.

Becerra, Marina (2009), Marxismo y feminismo en el primer socialismo argentino. Enrique Del Valle Iberlucea, Rosario: Prohistoria Ediciones.

Camarero, Hernán (2007), A la conquista de la clase obrera. Los comunistas y el mundo del trabajo en la Argentina, 1920-1935, Buenos Aires: Siglo XXI.

41. Las nuevas disposiciones fueron rápidamente editadas: PC, Sección Argentina de la III Internacional, Estatutos. 21 condiciones de la Internacional Comunista. Tesis sobre la Sindical Roja y Declaración de Principios, La Internacional, 1921.

42. Partido Comunista, Comisión del Comité Central, Esbozo de Historia del Partido Comunista de la Argentina, Buenos Aires: Anteo, 1947, p. 44. 
- (2017), Tiempos rojos. El impacto de la Revolución rusa en la Argentina, Buenos Aires: Sudamericana.

- y Carlos M. Herrera (eds.) (2005), El Partido Socialista en Argentina. Sociedad, politica e ideas a través de un siglo, Buenos Aires: Prometeo.

Campione, Daniel (2005), El comunismo en Argentina. Sus primeros pasos, Buenos Aires: Instituto Movilizador de Fondos Cooperativos-Centro Cultural de la Cooperación.

Corbière, Emilio J. (1984), Origenes del comunismo argentino (El Partido Socialista Internacional), Buenos Aires: CEAL.

- (1987), El marxismo de Enrique del Valle Iberlucea, Buenos Aires: CEAL.

Del Valle Iberlucea, Enrique (1934), La Revolución Rusa, Buenos Aires: Claridad.

Díaz, Hernán (2015), "El periódico Palabra Socialista (1912-1914) y los comienzos de la disidencia marxista en el PS", en Archivos de historia del movimiento obrero y la izquierda, año III, $\mathrm{n}^{\circ} 6$, pp. 95-114.

Doeswijk, Andreas (2013), Los anarco-bolcheviques rioplatenses (1917-1930), Buenos Aires: Cedinci.

Marianetti, Benito (1971), Enrique del Valle Iberlucea. Una honesta conducta frente a la Revolución Rusa, Buenos Aires: Sílaba.

Martinez Mazzola, Ricardo (2015), “¿Males pasajeros? El Partido Socialista frente a las consecuencias de la Ley Sáenz Peña”, en Archivos de historia del movimiento obrero y la izquierda, año III, $\mathrm{n}^{\circ}$ 6, marzo, Buenos Aires, pp. 53-72.

Pittaluga, Roberto (2015), Soviets en Buenos Aires. La izquierda de la Argentina ante la revolución en Rusia, Buenos Aires: Prometeo.

Poy, Lucas (2014), "Juan B. Justo y el socialismo argentino ante la Primera Guerra Mundial (1909-1915)”, en Politica y Cultura, n 42, México, pp. 155-181.

Walter, Richard J. (1977), The Socialist Party of Argentina, 1890-1930, Texas: The University of Texas at Austin.

$$
* * *
$$

Titulo: "Socialism, the internationalist left and the nascent communism of Argentina in the face of the Russian Revolution of 1917".

Resumen: Este artículo estudia las primeras influencias de la Revolución Rusa de 1917 dentro de las izquierdas argentinas, en particular las orientaciones teóricas, políticas y estratégicas adoptadas por el Partido Socialista, la tendencia de izquierda de esa organización y el emergente comunismo. Este análisis brinda elementos para comprender los modos en que estas corrientes entendieron el sentido de la revolución y las potencialidades y limites del programa reformista, democrático y/o revolucionario, así como sus definiciones acerca del sujeto del cambio social y el lugar de las masas en los acontecimientos. 
Palabras clave: Revolución Rusa - Partido Socialista - Izquierda socialista Comunismo

Abstract: This article studies the first influences of the Russian Revolution of 1917 in the Argentine left, in particular the theoretical, political and strategic orientations adopted by the Socialist Party, the tendency of left of that organization and the emerging communism. This analysis provides elements to understand the ways in which these currents understood the meaning of the revolution and the potentials and limits of the reformist, democratic and revolutionary program, as well as their definitions about the agent of change social and the place of the masses in the events.

Keywords: Russian Revolution - Socialist Party - Socialist Left - Communism 